\title{
Evaluation of OSCAR ocean surface current product in the tropical Indian Ocean using in situ data
}

\author{
Rajesh Sikhakolli ${ }^{1, *}$, Rashmi Sharma ${ }^{1}$, Sujit Basu ${ }^{1}$, \\ B S GOHIL ${ }^{1}$, ABhiJit SARKAR ${ }^{1}$ and $\mathrm{K}$ V S R Prasad ${ }^{2}$ \\ ${ }^{1}$ Atmospheric and Oceanic Sciences Group, Space Applications Centre (ISRO), Ahmedabad 380 015, India. \\ ${ }^{2}$ Department of Meteorology and Oceanography, Andhra University, Visakhapatnam 530 003, India. \\ *Corresponding author.e-mail: srajesh@sac.isro.gov.in
}

The OSCAR (ocean surface current analysis real-time), which is a product derived from various satellite observations, has been evaluated in the tropical Indian Ocean (TIO) in two different ways. First, the OSCAR-derived monthly climatology has been compared with available drifter-derived climatology in the TIO. From the comparison of the two climatologies, one can infer that OSCAR product is able to capture the variabilities of the well-known surface current systems in the TIO reasonably well. Fourier analysis of the major current systems, as reproduced by OSCAR, shows that the dominant annual and semiannual periodicities, known to exist in these systems, have been faithfully picked up by OSCAR. Next, the evaluation has been carried out by comparing the OSCAR currents with currents measured by moored buoys. The zonal component of OSCAR-current is in good agreement with corresponding component of buoy-observed current with a correlation exceeding 0.7 , while the match between the meridional components is poorer. The locations of the peaks of the mean and eddy kinetic energies are matching in both the climatologies, although the peak in the drifter climatology is stronger than the same in the OSCAR product. Finally, an important feature of Indian Ocean circulation, namely the reverse Wyrtki jet, occurring during anomalous dipole years, has been well-reproduced by OSCAR currents.

\section{Introduction}

Monitoring the variations of ocean surface currents is extremely important for climate studies as these currents are the major transporters of heat and salt. Surface current in the Indian Ocean displays the unique feature of annual reversal in response to annually reversing monsoon winds (Shenoi et al. 1999). Traditionally, ocean currents have been measured by ships, moored current meters and drifting buoys. However, the situation in the Indian Ocean is worse than in the Atlantic and the Pacific because of the relative scarcity of in situ data. Nevertheless, Hastenrath and Greischar (1991) studied the seasonal variability of surface circulation in the tropical Indian Ocean (TIO) using long-term observations of surface wind field and ship drift measurements.

Later, Shenoi et al. (1999) studied the surface circulation in the TIO by deriving a monthly climatology of ocean surface currents from the drifting buoy observations in the TIO collected from 1976 to 1998. Lagerloef et al. (1999) used satellite altimetry and vector wind data to analyse surface velocity during 1992-1999. In a study of somewhat similar nature, Shankar et al. (2002) studied the ocean surface currents in the Indian Ocean by combining geostrophic current from sea surface height (SSH) measurements and Ekman current from sea surface wind (SSW) field. However, neither

Keywords. Ocean surface current; remote sensing; buoy currents; drifter data; Indian Ocean circulation. 
Lagerloef et al. (1999) nor Shankar et al. (2002) could correctly reproduce the equatorial current features.

The problem of estimating satellite-derived nearsurface velocity in the equatorial area was solved by Bonjean and Lagerloef (2002). They used three surface variables, namely SSH, SSW and sea surface temperature (SST), all available from satellite measurements, to derive the surface current product, known as ocean surface current analysis realtime (OSCAR). The method of deriving the surface current is based on the resolution of quasi-steady quasi-linear momentum equations, neglecting local acceleration. Equatorial velocities are obtained by solving a weak formulation of the momentum equations using a basis set of orthogonal polynomials. This formulation of Bonjean and Lagerloef (2002) differs from the one used in Lagerloef et al. (1999) in many ways. A simplified buoyancy force, solely a function of SST, is retained in the vertical hydrostatic balance. This force is absent in the earlier version (Lagerloef et al. 1999). In this way, the SST enters the computation of vertically averaged velocity. Apart from this, the net drag force required in this computation uses eddy viscosity formulation, whereas in the earlier version, a Rayleigh friction was used. Moreover, the velocity shear is depth-dependent, which implies a higher-order turbulence closure parameterization than the earlier version. All these factors, in a combined fashion, have contributed to the superior performance of the present algorithm for generating ocean surface current.

Validation and error analysis of the OSCAR product was carried out in the tropical Pacific Ocean (Johnson et al. 2007). The OSCAR product is, however, a global product. Thus there is a pressing need to validate this product in the other basins of the world ocean, e.g., in the Indian Ocean. The present study is motivated by this need. In the present study, monthly climatology of OSCAR ocean surface currents in the TIO has been generated and this has been compared with climatology of surface currents based on drifter data. The OSCAR product has also been validated by comparing it with available moored current meter data in the TIO.

Since the present paper is basically about surface currents from various data sources and their intercomparison, it would be beneficial for the readers to have a look at the major surface currents in the Indian Ocean (Shenoi et al. 1999; Schott and McCreary 2001; Shankar et al. 2002). Accordingly, in figure 1, we provide such a schematic. Figure 1(a) shows the major currents during winter, while the major currents during summer are shown in figure 1(b). In winter, the surface current pattern is similar to the pattern prevailing in the two other major ocean basins, namely the Pacific and the Atlantic. The South Equatorial Current (SEC), the Equatorial Current (EC), the Equatorial Counter Current (ECC) and the Northeast Monsoon Current (NMC) are shown in figure 1(a). Associated boundary currents such as the East African Coastal Current (EACC), the East India Coastal Current (EICC) and the West India Coastal Current (WICC) have also been depicted. During summer, the westward NMC is replaced by eastward flowing Southwest Monsoon Current (SMC). The EICC and WICC directions are reversed, while the Somali Current (SC) starts flowing northward, instead of southward. There is also another major current system in the Indian Ocean, which is the strong eastward flowing jet known as the Wyrtki Jet (WJ), which appears during the transition periods, April-May and October-November (Wyrtki 1973). Since figure 1 is a description of major summer and winter currents, the WJ has not been shown in figure 1 . However, the representation of WJ in OSCAR product has been described at an appropriate place. In figure 1, we also show the locations of the RAMA moored buoys used in this study by asterisk symbols.

\section{Data}

\subsection{OSCAR current data}

The OSCAR data used in the present study span the period from 1993 to 2008. The data are available at 5-day intervals and at $1^{\circ} \times 1^{\circ}$ spatial resolution for the TIO and are obtained from www.oscar.noaa.gov. The datasets are mainly built from the satellite data that have been collected since October 1992 during ongoing missions. SSH is gridded from TOPEX/Poseidon data for the period October 1992-June 2002 and from Jason-1 for the period July 2002 to the present (Johnson et al. 2007). SSW data are provided by the variationally analysed Special Sensor Microwave Imager (SSM/I) winds (Atlas et al. 1996) from October 1991 to September 2001 and the QuikSCAT gridded winds from the Center for Ocean Atmosphere Prediction Studies (August 2001 till present). The SST data used in generating these OSCAR currents are Reynolds and Smith's version 2 SST, a product blended from the satellite and in situ data (Reynolds et al. 2002).

\subsection{Drifter buoy data}

Under the auspices of the drifting buoy programme, the National Institute of Oceanography (NIO), Goa, is maintaining and archiving the satellite-tracked drifting buoy data for the TIO. 

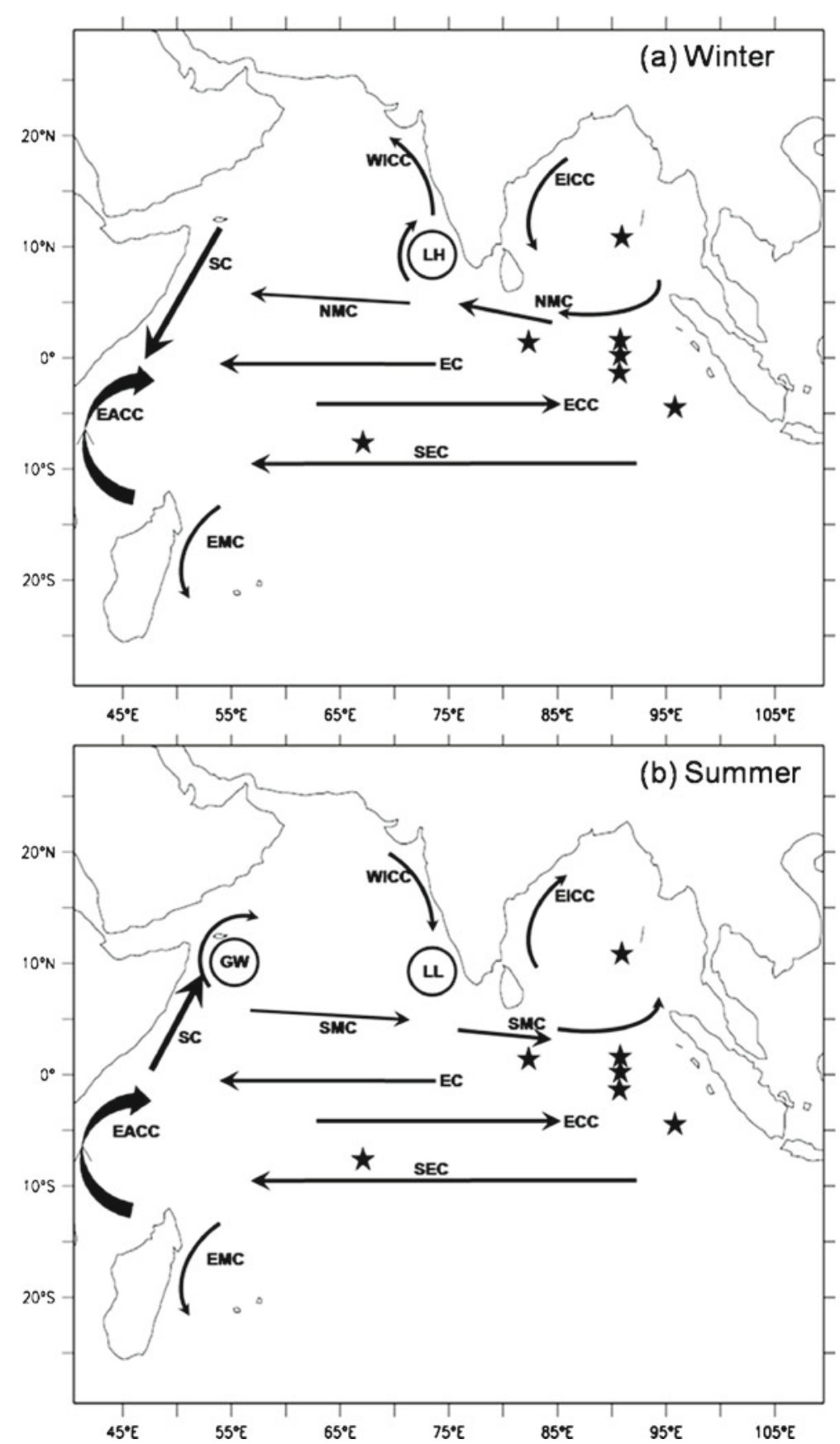

Figure 1. Schematic of major surface currents in the Indian Ocean during (a) winter and (b) summer. The asterisks show the moored buoy locations used for comparison.

Recently, a monthly climatology of ocean surface currents has been developed from this data on a $2^{\circ} \times 2^{\circ}$ grid from these drifting buoy observations in the TIO using data collected from 1985 to 2006 (www.nio.org). Shenoi et al. (1999) have described the methodology used to develop this climatology. In the present study, this drifter climatology has been used to validate the important large-scale features of the TIO circulation that are reflected in the OSCAR product.

\subsection{Moored current meter data}

A key element in the Indian Ocean Observing System (IndOOS) is the basin-scale array of moored buoys, known as, research moored array for African-Asian-Australian monsoon analysis and prediction (RAMA). It is designed specifically to study large-scale ocean-atmosphere interaction, mixed-layer dynamics and ocean circulation related to the monsoons on intraseasonal 
to decadal time-scales. The details of RAMA buoy network and their implementation plan and scientific objectives have been presented recently in a paper by McPhaden et al. (2009). In the present study, the time series data of ocean currents from buoys of this network in the Indian Ocean are used.
3. Results

\subsection{Comparison with climatology}

Since there are very few moored buoys with current measurements in the TIO, a basin scale comparison
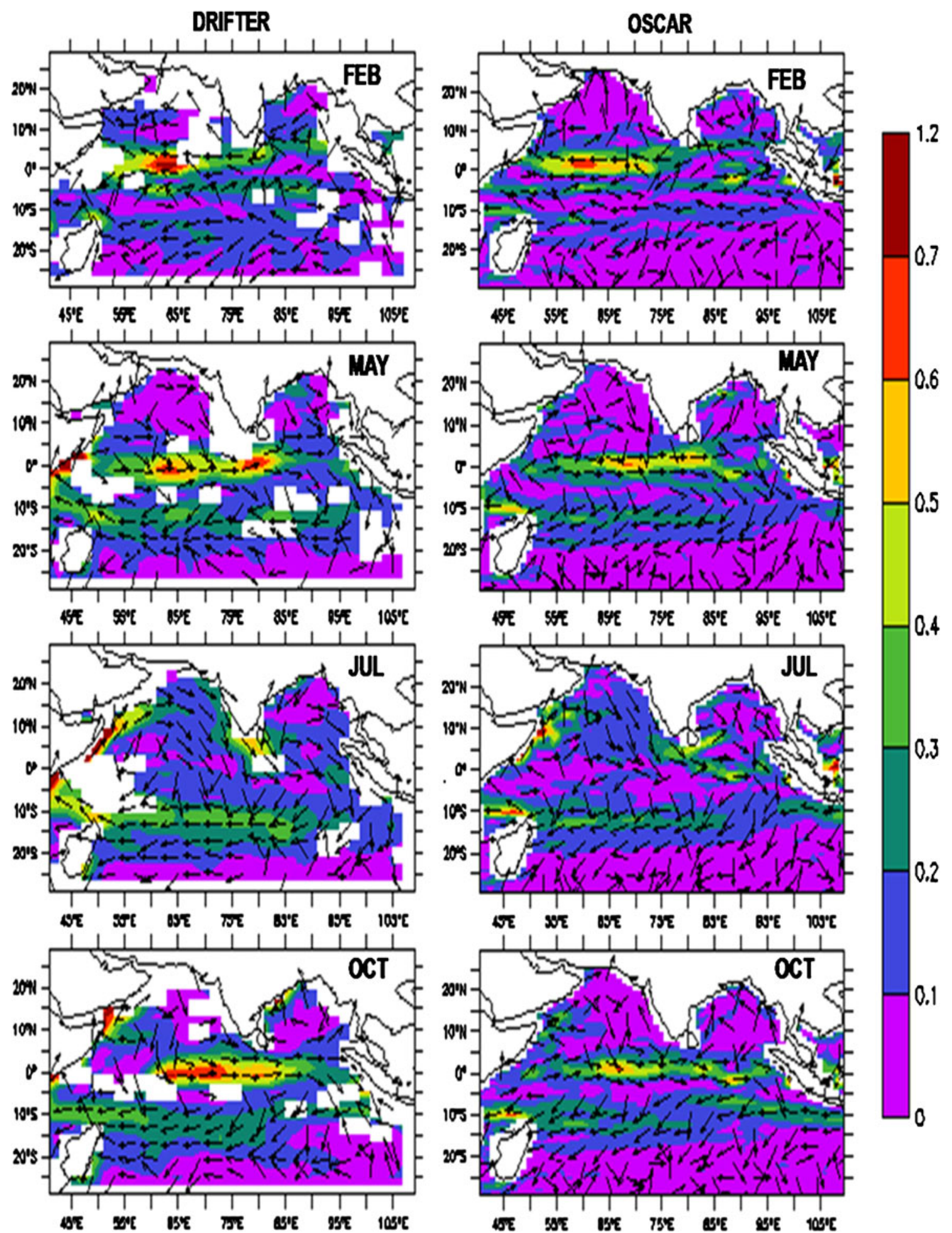

Figure 2. Monthly means of ocean surface current $\left(\mathrm{ms}^{-1}\right)$ from OSCAR (left panel) and drifter data (right panel) for 4 chosen months. Colour shading shows the magnitudes while the arrows (of fixed length) show the directions. 
of OSCAR product with in situ data is not really feasible. Hence, we took the alternative route of comparing the OSCAR-derived monthly climatology with drifter-derived climatology. Accordingly, a new monthly climatology was derived in the TIO from 16 years (1993-2008) of OSCAR currents. In figure 2 , we show the monthly climatologies of surface currents from the OSCAR and drifter data. However, we show only four representative months instead of all the 12 months, because in these four months, the major current systems are well-reflected in both the climatologies. From figure 2, it is apparent that the OSCAR climatology is able to capture the large-scale ocean circulation features in the TIO reasonably well. Thus, during the northeast monsoon season (represented here by the typical month of February), the characteristic circulation features such as the westwardflowing WMC north of equator as well as the poleward-flowing WICC are well-represented in the OSCAR climatology. The anti-cyclonic (clockwise) surface circulation in the Bay of Bengal (BoB), observed in the drifter climatology, is also wellcaptured by the OSCAR climatology. Moreover, the other known features such as the ECC and SEC, which are reflected in the drifter climatology, are equally well-visible in the OSCAR climatology. During the monsoon transition months of May and October, the strong eastward flowing WJ with current speed of about $0.6 \mathrm{~ms}^{-1}$ is vividly noticeable in the OSCAR climatology. During the peak southwest monsoon month of July, the strong northeastward SC can be clearly observed in the OSCAR climatology. However, the intensity of SC is somewhat underestimated. During this month, i.e., during July, the eastward flowing SMC is observed just north of the equator.

In figure 3 , we show the monthly difference between OSCAR and drifter climatologies for the same 4 months. Here, only the difference between the magnitudes is shown. During all the 4 months, the differences are less than $0.2 \mathrm{~ms}^{-1}$ in most parts of the study area. The difference exceeds this value only at isolated places and in some months. Thus, large difference between the two magnitudes is noticed near the Somali coast during May, July and October. In the equatorial Indian Ocean (between $60^{\circ}$ and $80^{\circ} \mathrm{E}$ ), there are large differences
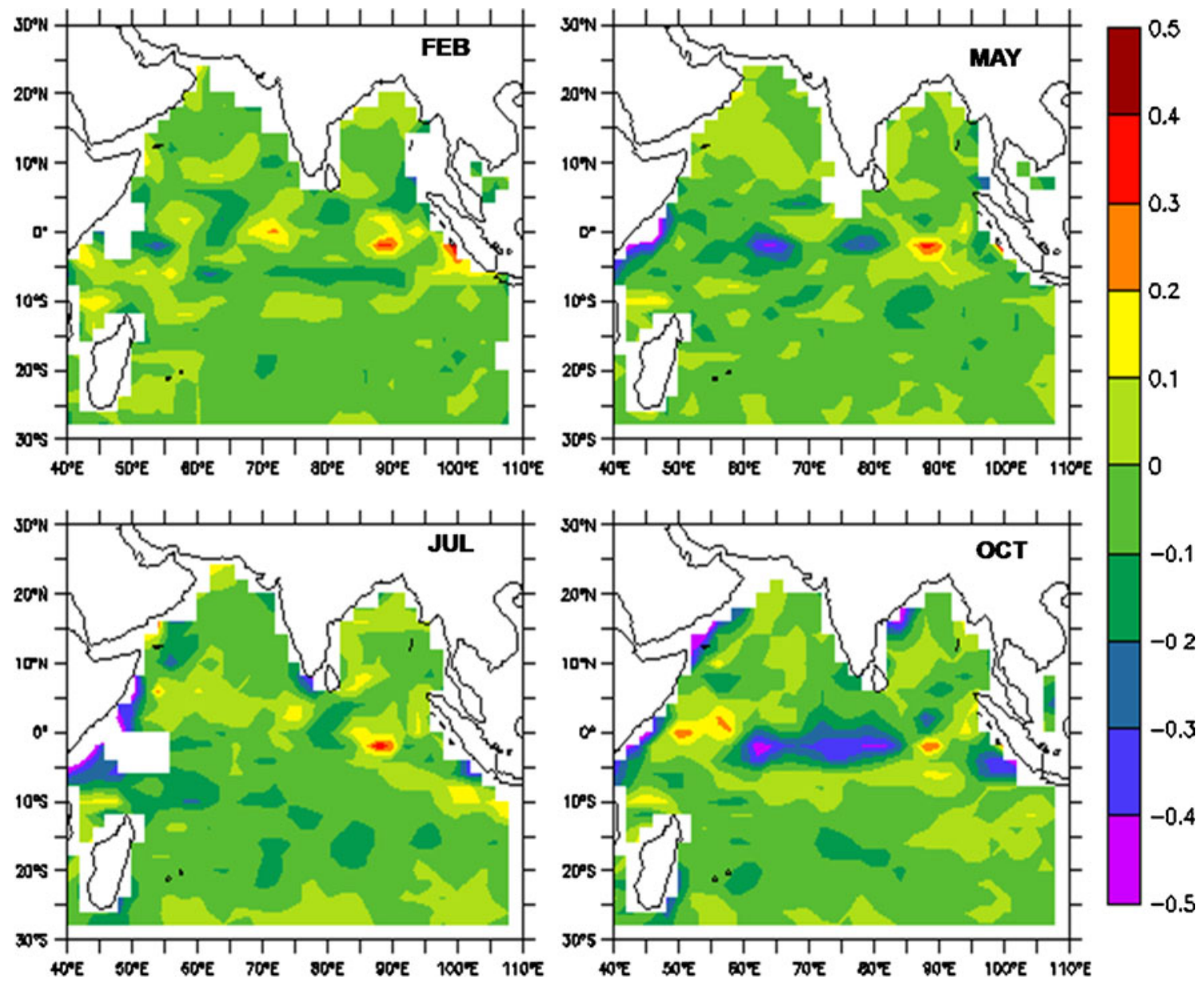

Figure 3. Difference between OSCAR and drifter-derived climatologies in terms of current speed (ms ${ }^{-1}$ ) for the same 4 months as in figure 2. 
in May and October. The differences are more pronounced in October than in May. There are also large differences in the SMC regime east of Sri Lanka.

\subsection{Fourier analysis of the major current systems}

In the previous section, we have compared the OSCAR climatology with drifter climatology and have shown that the major current systems of the TIO are well-captured by the OSCAR product. Another way of qualitatively evaluating the OSCAR product is to see whether the major periodicities known to exist in the major current systems are well-captured by the OSCAR product. Accordingly, in figure 4, we show the results from Fourier analysis carried out on the time series of the current speed for some of these current systems. In this figure, EC signifies the equatorial current and $\mathrm{MC}$ denotes the monsoon current. The name $\mathrm{MC}$ is just a generic name. During winter, the corresponding current is known as NMC (schematically shown in figure 1a), while during summer, the current is known as SMC (schematically shown in figure 1b). Except for EC, the annual periodicity is dominant in each of these current systems, which was only to be expected. In the EC regime, the semi-annual periodicity is also quite strong. This semiannual periodicity owes its origin to the presence of strong eastward jets (the Wyrtki jets) twice a year (April/May and September/October) and has been noted by many researchers. We mention here just the two well-known theoretical studies (Jensen 1993; Han et al. 1999). It is indeed gratifying to see that this well-known semi-annual periodicity is present in the EC computed by OSCAR algorithm.

\subsection{Seasonal march of surface currents}

So far, we have shown the comparison of OSCAR and drifter climatologies for four representative months. We have also found that the major periodicities of the known important current systems are well-captured by the OSCAR product. Nevertheless, it is still instructive to investigate whether

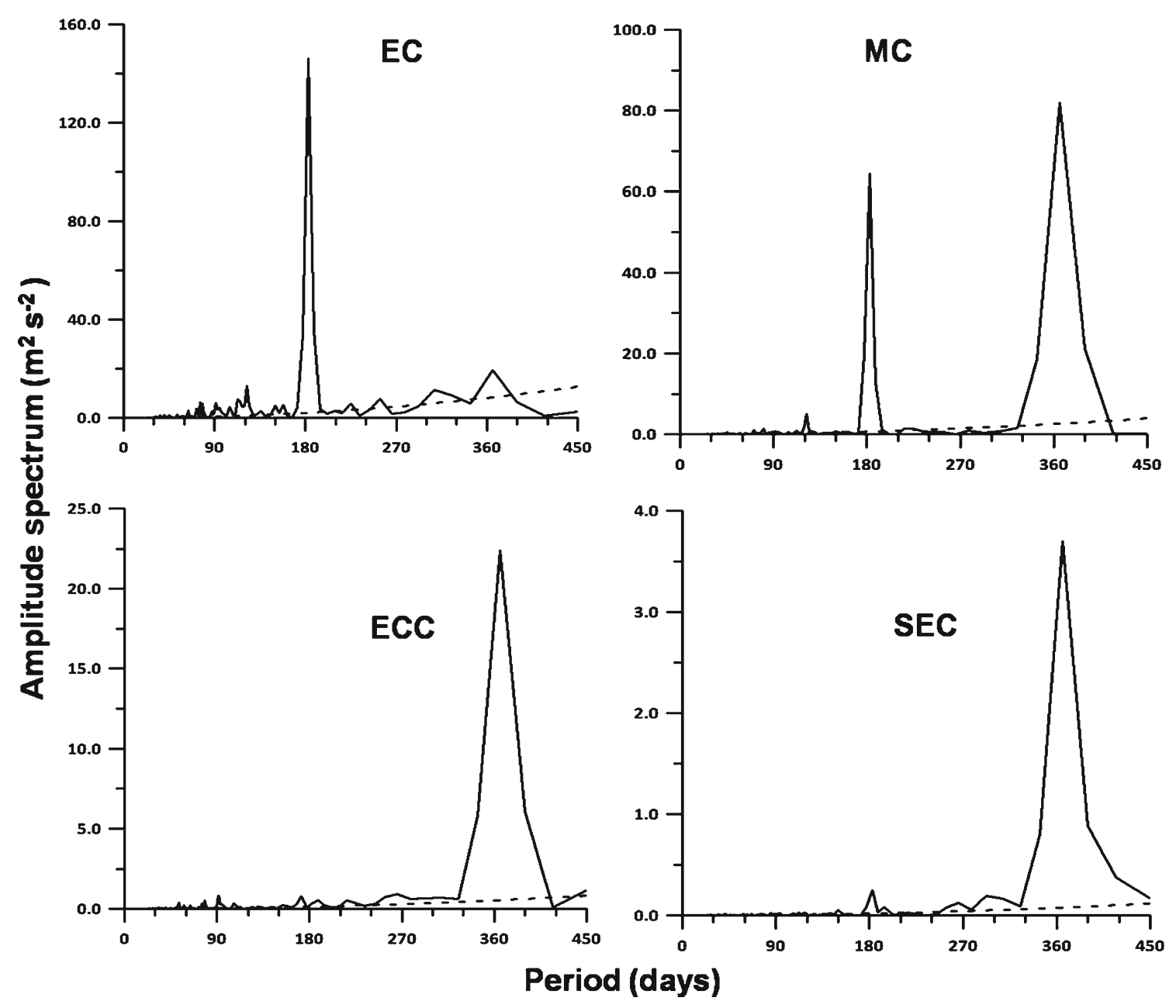

Figure 4. Fourier analysis of the major current systems in the TIO. The dashed curves represent the $99 \%$ confidence level. 
the OSCAR product is able to pick up the seasonal march of the major current systems in the TIO reasonably well. For this purpose, we have averaged the currents in few representative boxes and have displayed the time evolution of these spatially averaged currents. In the same figure, the time evolution of the corresponding currents from drifter climatology (averaged in the same boxes as the OSCAR currents) are also shown. The meridional components of these box averaged currents are generally quite weak. Hence, the comparisons are shown only for the zonal components. In what follows, the words 'box averaged' would be dropped while describing the seasonal march. The box locations are provided in table 1 . The repeated use of the word 'zonal' would also be avoided.

Figure 5 shows this seasonal march. The premonsoon peak of the ECC appearing in the drifter data is smoother in the OSCAR data. With the onset of the southwest monsoon, the intensity decreases in both the datasets. The secondary maximum in October is observed only in the drifter climatology. The EC peaks during the two transition periods and has minima during January

Table 1. Box boundaries used in the present study to describe major current systems in the Indian Ocean.

\begin{tabular}{lcc}
\hline Current system & Latitude range & Longitude range \\
\hline Equatorial Counter Current (ECC) & $2^{\circ}-8^{\circ} \mathrm{S}$ & $60^{\circ}-80^{\circ} \mathrm{E}$ \\
Equatorial Current (EC) & $2^{\circ} \mathrm{N}-2^{\circ} \mathrm{S}$ & $60^{\circ}-90^{\circ} \mathrm{E}$ \\
Monsoon Current (MC) & $3^{\circ}-6^{\circ} \mathrm{N}$ & $79^{\circ}-82^{\circ} \mathrm{E}$ \\
South Equatorial Current (SEC) & $8^{\circ}-16^{\circ} \mathrm{S}$ & $60^{\circ}-80^{\circ} \mathrm{E}$ \\
Somali Current (SC) & $4^{\circ}-8^{\circ} \mathrm{N}$ & $48^{\circ}-50^{\circ} \mathrm{E}$ \\
\hline
\end{tabular}

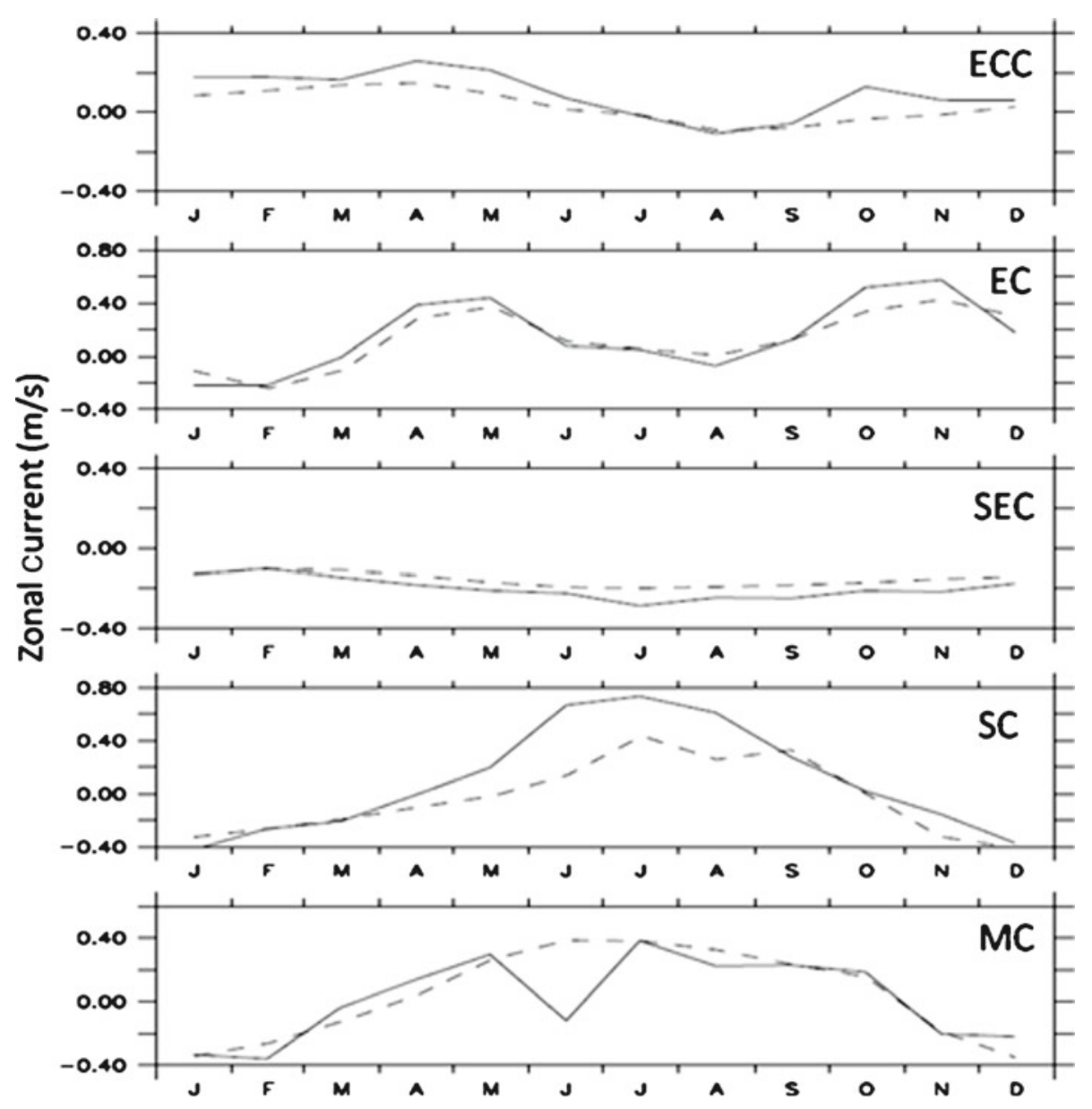

Figure 5. Seasonal march of major currents $\left(\mathrm{ms}^{-1}\right)$ in the TIO from OSCAR (dashed line) and drifter (thick line) climatologies. 
and February. The peaks are the manifestations of the well-known Wyrtki jets, which have made their presence felt during the Fourier analysis of EC (figure 4) through the appearance of strong semiannual periodicity.

The SEC peaks in July, the peak being smoother in OSCAR climatology. The well-known reversal of SC from southward to northward direction with the onset of southwest monsoon is also reasonably well-picked up by the OSCAR, although the peak intensity is much less than in the drifter climatology

The MC in figure 5 is towards west during January and February, and from March onwards the current direction reverses and becomes eastward with maximum intensity during southwest monsoon season. This current is well-represented in both the climatologies, with the exception of the valley in June. This is conspicuous by its absence in the OSCAR product.

\subsection{Comparison with RAMA buoy data}

From the previous sections, one can conclude that the large-scale circulation features of the TIO have been reasonably well-captured by the OSCAR product. Nevertheless, comparison with in situ data, e.g., observed by moored buoys, is still called for. After all, there is no substitute of actual in situ observations for validation of a remotely sensed product. Accordingly, in figures 6 and 7 , we show the 10-day average comparison
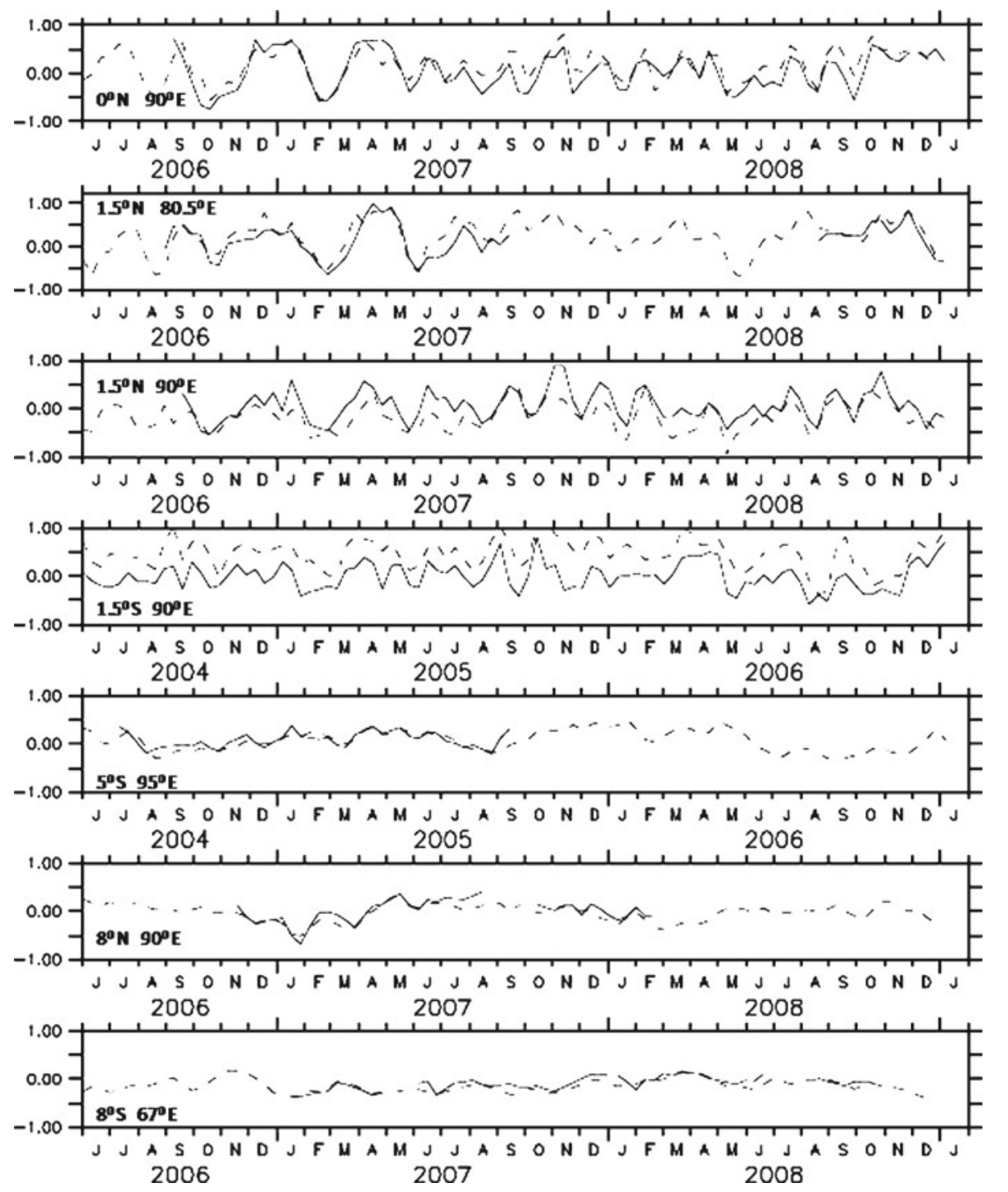

Figure 6. Comparison between OSCAR current (dashed line) and RAMA buoy observed zonal current (thick line). For easier comprehension of the figures, the length of the time axis is same in all the panels (roughly 2.5 years), although there are large data gaps in buoy data at many locations. Also, the time periods vary from buoy to buoy. All the currents are in $\mathrm{ms}^{-1}$. 

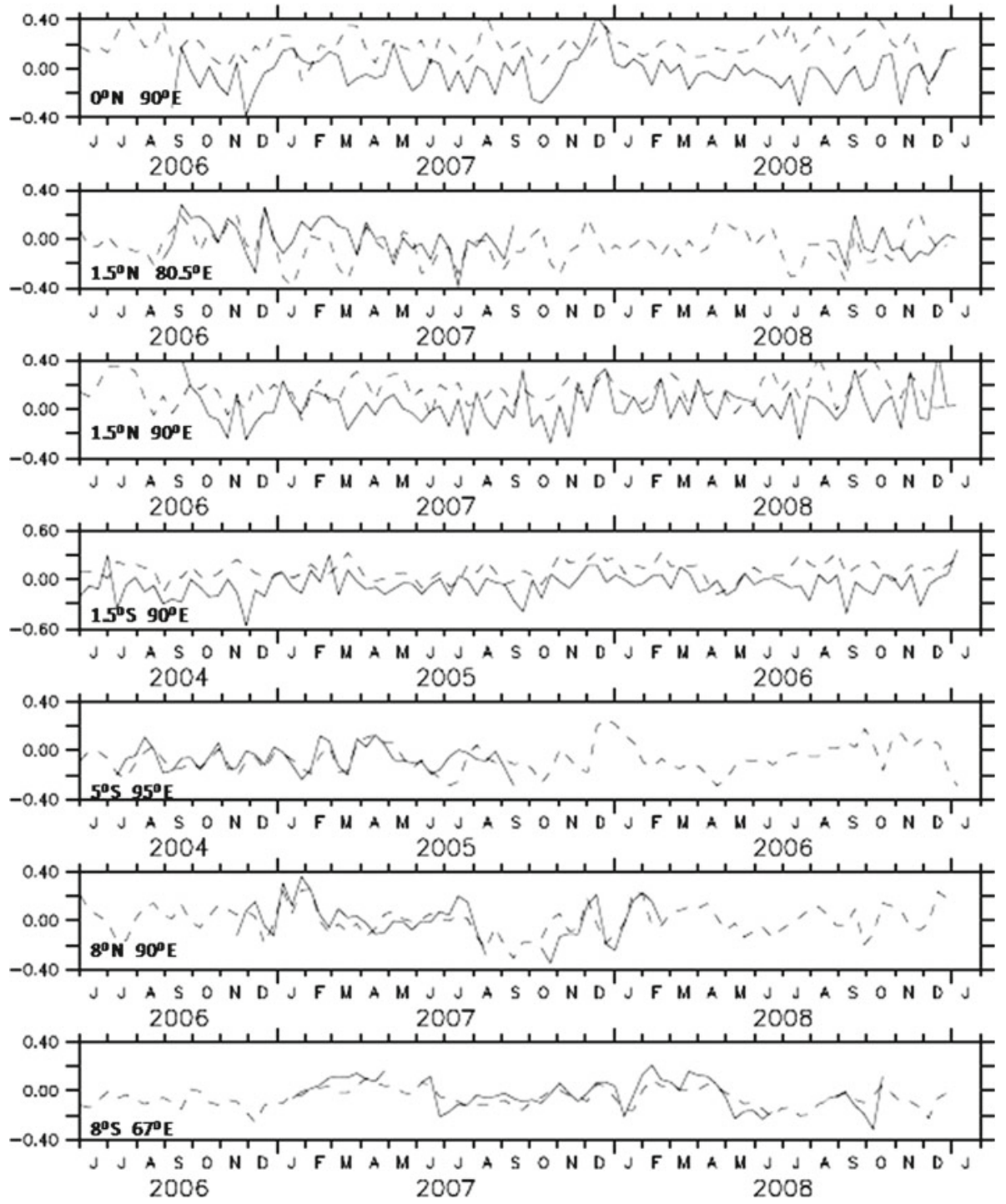

Figure 7. Same as in figure 6 except for meridional current.

Table 2. Statistics of comparison between OSCAR and RAMA buoy zonal (meridional) current $\left(\mathrm{ms}^{-1}\right)$.

\begin{tabular}{|c|c|c|c|c|c|c|}
\hline Latitude & Longitude & Start date & End date & $\operatorname{Bias}\left(\mathrm{ms}^{-1}\right)$ & $\begin{array}{l}\text { Root mean square } \\
\quad \text { error }\left(\mathrm{ms}^{-1}\right)\end{array}$ & $\begin{array}{c}\text { Correlation } \\
\text { (R) }\end{array}$ \\
\hline-8 & 67 & 09/01/07 & $30 / 10 / 08$ & $-0.050(-0.021)$ & $0.101(0.075)$ & $0.79(0.74)$ \\
\hline 8 & 90 & $9 / 11 / 06$ & 03/03/08 & $-0.084(0.002)$ & $0.133(0.119)$ & $0.90(0.63)$ \\
\hline-5 & 95 & $21 / 10 / 01$ & $20 / 09 / 05$ & $-0.014(-0.048)$ & $0.140(0.107)$ & $0.75(0.59)$ \\
\hline-1.5 & 90 & $18 / 10 / 01$ & 09/07/07 & $0.467(0.175)$ & $0.503(0.235)$ & $0.78(0.34)$ \\
\hline 1.5 & 90 & $12 / 09 / 06$ & $03 / 06 / 08$ & $-0.256(0.111)$ & $0.333(0.192)$ & $0.77(0.15)$ \\
\hline 1.5 & 80.5 & $27 / 08 / 06$ & $21 / 09 / 07$ & $0.143(-0.075)$ & $0.279(0.173)$ & $0.83(0.48)$ \\
\hline 0 & 90 & $27 / 07 / 06$ & $03 / 12 / 08$ & $0.123(0.223)$ & $0.262(0.270)$ & $0.79(0.18)$ \\
\hline
\end{tabular}

of zonal and meridional currents in OSCAR with the corresponding quantities measured by RAMA buoys. The comparison statistics is provided in table 2. It is quite evident from the figures that the OSCAR currents are able to capture the mesoscale variability reasonably well. The comparison shows good agreement between the two zonal currents for all the buoys, except for the one at $1.5^{\circ} \mathrm{S}$ and $90^{\circ} \mathrm{E}$, in this case, there is a high bias. From the displayed statistics in table 2 , it is also quite clear that the overall correlation is greater than 0.7 for the zonal component and is around 0.5 for the meridional component, except for a few buoys near the equator. It may be worthwhile to mention here that this 
result (better match for the zonal currents than for the meridional currents) is completely analogous to the similar result obtained by Johnson et al. (2007) in the Pacific.

\subsection{Mean and eddy kinetic energy}

Using the formulations given in Shenoi et al. (1999), the distributions of kinetic energy of the mean flow $\left(E_{\mathrm{M}}\right)$ and eddy kinetic energy $\left(E_{\mathrm{E}}\right)$, the temporally varying part, representing the variance of the velocity field due to fluctuations spanning a broad range of time and space scales, are presented in figure 8. Distribution of mean kinetic energy from both the climatologies is of similar nature with a peak of the order of $800 \mathrm{~cm}^{2} \mathrm{~s}^{-2}$ at isolated pockets. There is a zonal band coinciding with the SEC, where $E_{\mathrm{M}}$ is of the order of $200 \mathrm{~cm}^{2} \mathrm{~s}^{-2}$. At the western end, the energy reaches a peak of about $800 \mathrm{~cm}^{2} \mathrm{~s}^{-2}$. This is somewhat underestimated, compared to the drifter climatology, where the energy is of the order of $300 \mathrm{~cm}^{2} \mathrm{~s}^{-2}$ almost everywhere, except for some regions where it reaches the peak of $800 \mathrm{~cm}^{2} \mathrm{~s}^{-2}$. There are other discrepancies also. OSCAR shows high $E_{\mathrm{M}}$ near the eastern boundary, but the high energy regimes in the drifter are in two pockets much farther west.
OSCAR also does not pick the high $E_{\mathrm{M}}$ just south of Sri Lanka. In the Arabian Sea and BoB regions, the $E_{\mathrm{M}}$ did not exceed $100 \mathrm{~cm}^{2} \mathrm{~s}^{-2}$. The lowest values of $E_{\mathrm{M}}$ are observed in the mid-Arabian Sea and mid-BoB. In the Arabian Sea and BoB, the distribution of eddy kinetic energy $\left(E_{\mathrm{E}}\right)$ due to the perturbations of the surface velocity about the mean flow is much higher than $E_{\mathrm{M}}$, which indicates that most of the kinetic energy of the surface flow is in the eddy field. $E_{\mathrm{E}}$ has a peak in the equatorial region as well as in the western basin in both the climatologies.

\subsection{Interannual variability of the EC}

In this section, interannual variability of the EC is investigated. The reason for picking only this current is the following. It is well-known that there is an Indian Ocean dipole (Saji et al. 1999; Webster et al. 1999) generally abbreviated as IOD. The positive IOD occurs during anomalous years with anomalous cooling in the south Equatorial Indian Ocean (SEIO) and anomalous warming in the Western Indian Ocean (WIO). During the period of our study, two dipole events occurred in 1997 and 2006, which co-occurred with El Niño events in the Pacific. This co-occurrence led to
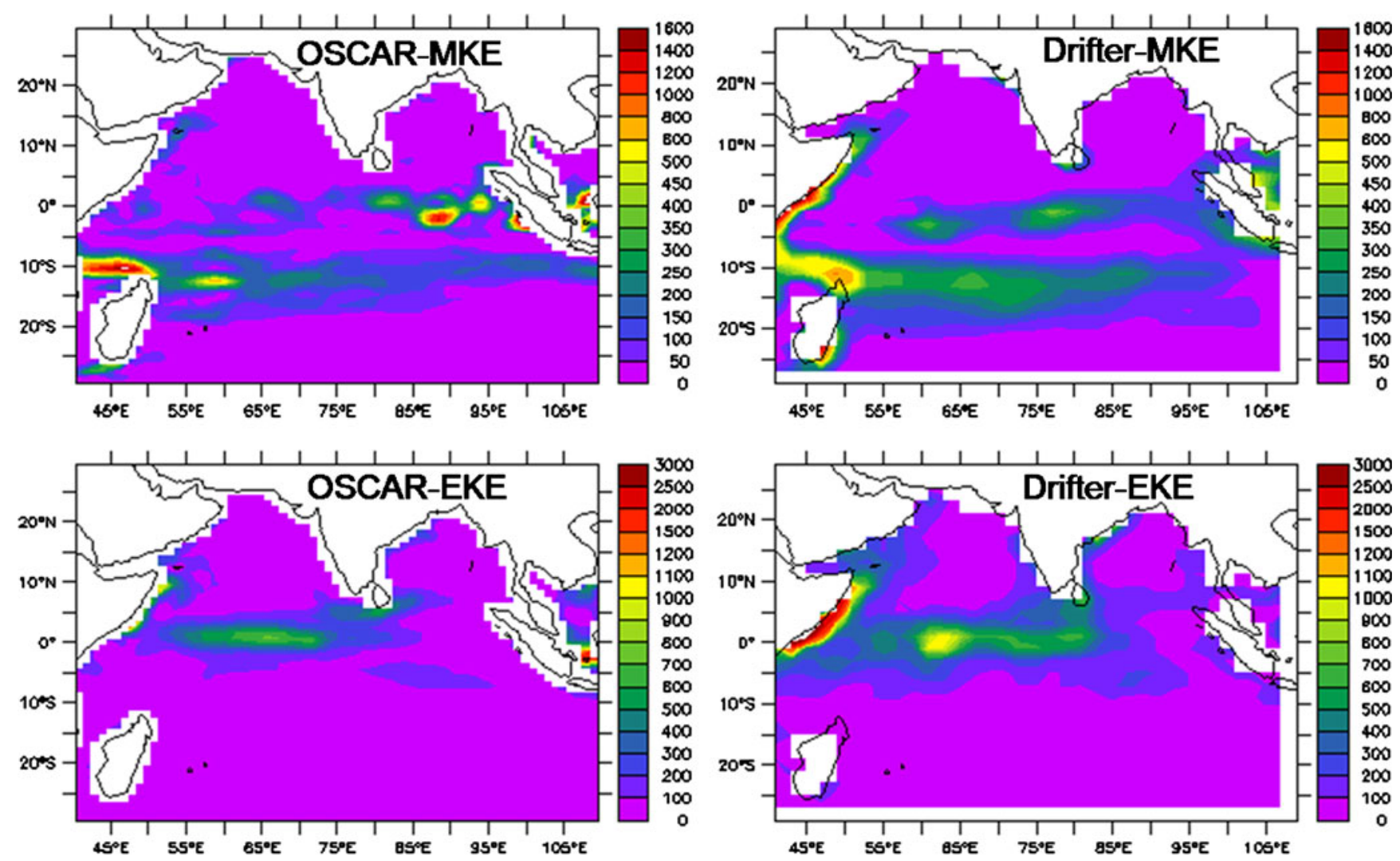

Figure 8. Distribution of mean and eddy kinetic energy per unit mass $\left(\mathrm{cm}^{2} \mathrm{~s}^{-2}\right)$ from OSCAR and drifter data. 


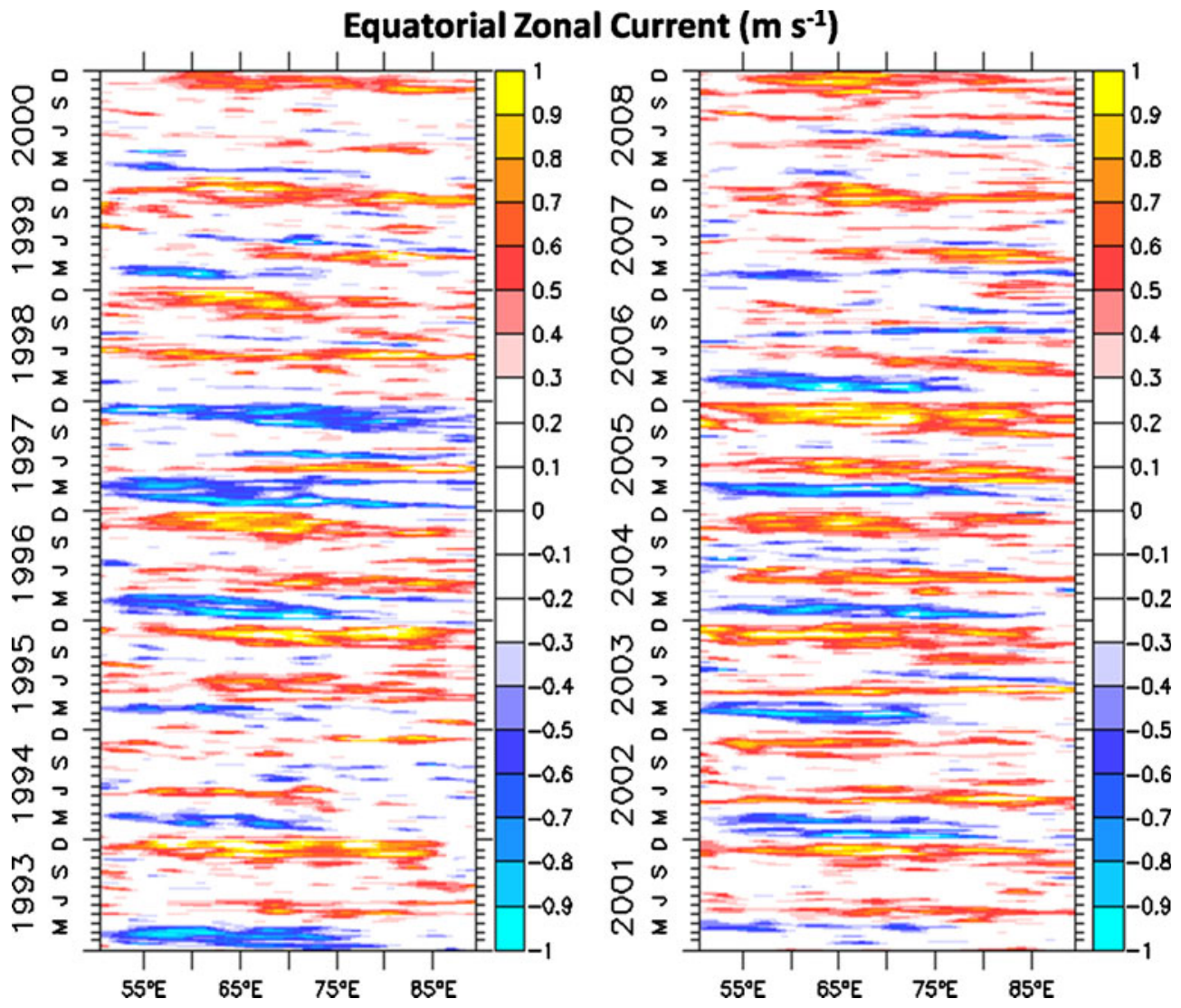

Figure 9. Interannual variability of equatorial current (in $\mathrm{ms}^{-1}$ ).

quite strong anomalous circulation features, which are described below. There was a reversal of the eastward flowing equatorial jet and Sharma et al. (2007) coined the phrase RWJ for the same, while the cyclonic circulation during this period in the $\mathrm{BoB}$ reverses and becomes anticyclonic (Rao et al. 2002; Thompson et al. 2006). Although the reversal of BoB circulation during the dipole years has been observed in the OSCAR products, the corresponding figures are not shown here for the economy of space. Nevertheless, it is quite interesting to see whether the RWJ is well-pronounced in the OSCAR product. It may be worthwhile to point out that, apart from Sharma et al. (2007), such a direction reversal of surface current (from eastward to westward) during a dipole event, has been noted by other modellers also (Murtugudde et al. 2000; Masson et al. 2004; Thompson et al. 2006). Accordingly in figure 9, we show the time-longitude plot of the EC as revealed by the zonal component of the OSCAR. The mentioned IOD events are clearly reflected in these plots, albeit with variable intensities. One can clearly see the strong westward current of the order of $0.6 \mathrm{~ms}^{-1}$ during 1997 and 2006 IOD years which co-occurred with El Niño in the Pacific Ocean.

\section{Summary and discussion}

The OSCAR ocean surface current product, which is a product derived from three kinds of satellite observations by solving quasi-steady quasilinear momentum equations, has been evaluated in the TIO by comparing with drifter-derived climatology. Comparison with drifter-derived climatology leads to the conclusion that the product reproduces the major current systems of the TIO. It has been, however, observed that the OSCAR currents are relatively weak in the Somali region during the peak monsoon months. This weakness is possibly due to the inability of the OSCAR product to capture the short cross-shore length scales associated with boundary currents. The mean and eddy kinetic energy maps generated from the two climatologies show similar pattern of maxima in the western boundary currents and equatorial currents and minima in the Arabian Sea, BoB and southern Indian Ocean. Fourier analysis showed that the periodicities known to exist in these current systems have been well-captured by the OSCAR product.

Seasonal march of the major current systems has also been studied in certain representative boxes. 
It has been found that there is a reasonably good match between the zonal components of the two climatologies in the case of ECC, EC and SEC. Even MC (except for the isolated valley in June) is well-represented in OSCAR climatology. However, the same cannot be said with such confidence for the Somali current, and its possible reason has been mentioned earlier in this section.

Further evaluation has been done by comparing the OSCAR currents with currents measured by moored RAMA buoys in the TIO. This comparison shows that, generally speaking, there is a good agreement between the two with correlation exceeding 0.7 for the zonal component. For the meridional component, the correlation is not as high. Similar type of poor correlation was observed in the Pacific by Johnson et al. (2007). One has to note that near the equator, the local acceleration term becomes important in the momentum balance. In fact, this term becomes important in the vicinity of strong eddies also. Since algorithm used in generating OSCAR currents has neglected this term, it is to be expected that in these regions, there will be a mismatch between the OSCAR currents and in situ currents measured by buoys. The possibility of improving the fidelity of OSCAR product by including a time-derivative, has, in fact, been suggested by Johnson et al. (2007).

The anomalous dipole years with their associated reverse Wyrtki jets have also been wellreflected in the OSCAR product. Bearing in mind the previous study by Johnson et al. (2007), and the results of the present study, it can be said with some degree of satisfaction that OSCAR product has been able, at least to a large extent, to meet the long-standing demand of physical oceanographers to have at their disposal basin-scale currents observed at regular time intervals. This study assumes increasing importance for another reason. Although the QuikSCAT is not operational any more, the scatterometer onboard the Indian Oceansat-2 satellite (known as OSCAT) has started providing global wind product. It is planned to generate products using these data (which will be similar to the OSCAR product), in synergy with data from altimeter and radiometer onboard other satellites. In future, the altimeter products, used in such efforts, could also be supplemented by data from Indo-French SARAL/ALtiKa altimeter. Undoubtedly, such current products would be of immense use for validating numerical ocean circulation models as well as for assimilating in these models.

\section{Acknowledgements}

The authors thank the Director and Associate Director, Space Applications Centre; Deputy
Director, Earth, Ocean, Atmosphere, Planetary Sciences and Applications Area, for motivation. They would like to place on record their sincere gratitude to the Group Director, Atmospheric and Oceanic Sciences Group, for constant encouragement. Very special thanks are due to Dr Bipasha Paul Shukla for the FFT software. The authors also thank NOAA/OSCAR group for providing satellite-derived current data and NIO, Goa for drifter data on the Indian Ocean. The drifter data used in this study are obtained from www.nio.org and RAMA buoy data are from NOAA/PMEL website.

\section{References}

Atlas R, Hoffman R, Bloom S, Jusem J and Ardizzone J 1996 A multi-year global surface wind velocity dataset using SSM/I wind observations; Bull. Am. Meteor. Soc. $77869-882$.

Bonjean F and Lagerloef G S E 2002 Diagnostic model and analysis of the surface currents in the tropical Pacific Ocean; J. Phys. Oceanogr. 32 2938-2954.

Han W, McCreary J P, Anderson D L T and Mariano A J 1999 On the dynamics of the eastward surface jets in the equatorial Indian Ocean; J. Phys. Oceanogr. 29 2191-2209.

Hastenrath S and Greischar L 1991 The monsoon current regimes of the tropical Indian Ocean: Observed surface flow fields and their geostrophic and wind-driven components; J. Geophys. Res. 96 12,619-12,633.

Jensen T G 1993 Equatorial variability and resonance in a wind-driven Indian Ocean model; J. Geophys. Res. 98 22,533-22,552.

Johnson E S, Bonjean F, Lagerloef G S E, Gunn J T and Mitchum G T 2007 Validation and error analysis of OSCAR sea surface currents; J. Atmos. Ocean. Tech. 24 688-701.

Lagerloef G S E, Mitchum G T, Lukas R and Niiler P P 1999 Tropical Pacific near surface currents estimated from altimeter, wind and drifter data; J. Geophys. Res. 104 $23,313-23,326$.

Masson S, Boulanger J-P, Menkes C and Delecluse P 2004 Impact of salinity on the 1997 Indian Ocean dipole event in a numerical experiment; J. Geophys. Res. 109 C02002, doi: 10.1029/2003JC001807.

McPhaden M J et al. 2009 RAMA: The research moored array for African-Asian-Australian monsoon analysis and prediction; Bull. Am. Meteor. Soc. 459-480.

Murtugudde R, McCreary J P and Busalacchi A J 2000 Oceanic processes associated with anomalous events in the Indain Ocean with relevance to 1997-98; J. Geophys. Res. 105 3295-3306.

Rao A S, Behera S K, Masumoto Y and Yamagata T 2002 Interannual subsurface variability in the tropical Indian Ocean with a special emphasis on the Indian Ocean Dipole. Deep-Sea Res. - Part II 49 15491572.

Reynolds R W, Rayner N A, Smith T M, Stokes D C and Wang W 2002 An improved in situ and satellite SST analysis for climate; J. Climate 15 1609-1625.

Saji N H, Goswami B N, Vinayachandran P N and Yamagata T 1999 A dipole mode in the tropical Indian Ocean; Nature 401 360-363. 
Schott F A and McCreary J P 2001 The monsoon circulation of the Indian Ocean; Prog. Oceanogr. 51 1-123.

Shankar D, Vinayachandran P N and Unnikrishnan A S 2002 The monsoon currents in the north Indian Ocean; Prog. Oceanogr. 52 63-120.

Sharma R, Agarwal N, Basu S and Agarwal V K 2007 Impact of satellite derived forcings on numerical ocean model simulations and study of sea surface salinity variations in the Indian Ocean; J. Climate 20 871-890.

Shenoi S S C, Saji P K and Almeida A M 1999 Nearsurface circulation and kinetic energy in the tropical
Indian Ocean derived from Lagrangian drifters; J. Mar. Res. 57 885-907.

Thompson B, Gnanaseelan C and Salvekar P S 2006 Variability in the Indian Ocean circulation and salinity and its impact on SST anomalies during dipole events; J. Mar. Res. 64 853-880.

Webster P J, Moore A M, Loschnigg J P and Lebben R R 1999 Coupled ocean-atmosphere dynamics in the Indian Ocean during 1997-98; Nature 401 356-360.

Wyrtki K 1973 An equatorial jet in the Indian Ocean; Science 181 262-264.

MS received 23 December 2011; revised 4 July 2012; accepted 5 July 2012 